\title{
Lipophilicity Study of Thiazolo[3,2-a]pyrimidine Derivatives as Potential Bioactive Agents
}

\author{
Renata Studzińska, ${ }^{*}, a$ Renata Kołodziejska, ${ }^{b}$ Małgorzata Redka, ${ }^{a}$ Bożena Modzelewska- \\ Banachiewicz $z^{a}$ and Beata Augustyńska ${ }^{b}$ \\ ${ }^{a}$ Department of Organic Chemistry, Faculty of Pharmacy and ${ }^{b}$ Department of Biochemistry, Faculty of Medicine, \\ Collegium Medicum in Bydgoszcz, Nicolaus Copernicus University in Toruń, Toruń, Poland
}

\begin{abstract}
Systems containing fused thiazole and pyrimidine rings play a significant role in organisms due to their biological activity. Lipophilicity, as important parameter to expect biological activity of the compounds, was evaluated for 27 potentially active thiazolo[3,2-a]pyrimidine derivatives using chromatographic methods: reversed phase thin layer chromatography (RP-TLC) and reversed phase high performance liquid chromatography (RP-HPLC) methods. Methanol was used as the organic modifier of the mobile phases. The corresponding relationship between compound's structure and lipophilicity parameters $\left(\mathrm{R}_{\mathrm{M} 0}\right.$ and $\left.\log \mathrm{k}_{\mathrm{w}}\right)$ values were observed and featured. $\mathrm{R}_{\mathrm{M} 0}$ and $\log \mathrm{k}_{\mathrm{w}}$ parameters were compared with computed $\log \mathrm{P}$ values. For all of analyzed compounds, determined lipophilicity's parameters values are $>0$ which means that there are hydrophobic substances, soluble in the lipid phase. Simultaneously, these values are $<5$, i.e., are in accordance with Lipinski's rule in the range of lipophilicity. In the case of the possibility of their use as drugs, they will be active after oral application.
\end{abstract}

Keywords: lipophilicity, thiazolopyrimidine derivatives, high pressure liquid chromatography, thin-layer chromatography, biological activity

\section{Introduction}

Systems containing fused thiazole and pyrimidine rings play a significant role in organisms due to their biological activity. Thiazolo[3,2-a]pyrimidine derivatives, among which ritanserin and setoperone are examples (Figure 1).
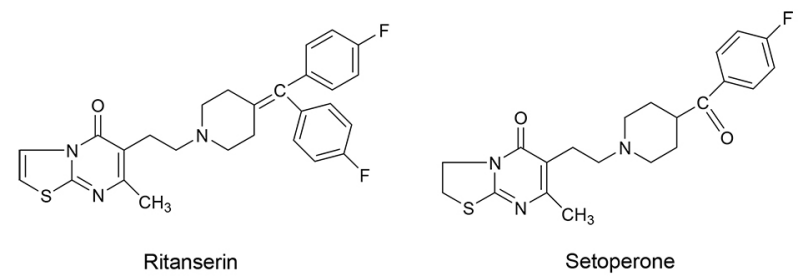

Figure 1. Ritanserin and setoperone as examples of biologically active compounds containing a thiazolopyrimidine system.

Ritanserin is one of the antagonist of $5 \mathrm{HT}_{2}$ serotonine receptors. ${ }^{1-4}$ Setoperone is an antagonist with high affinity and specificity for serotonine $5 \mathrm{HT}_{2}$ receptors. Moreover setoperone also binds to dopamine $\mathrm{D}_{2}$ receptors and it is effective as treatment of patients with chronic

*e-mail: rstud@cm.umk.pl schizophrenia. ${ }^{1,5-8}$ Other thiazolo[3,2-a]pyrimidine derivatives display antibacterial, ${ }^{9}$ antiviral, ${ }^{8,10}$ and analgesic ${ }^{11}$ activities as well as hypotensive. ${ }^{6}$

Lipophilicity is an important parameter to expect biological activity of the compounds. This parameter is expressed as a partition coefficient $\mathrm{P}$ or its decimal $\log a r i t h m(\log \mathrm{P})$. After introduced into the organism, the drug to reach its site of action must overcome a number of barriers in the form of biological membranes. Transport of drugs through cell membranes often proceed by way of passive diffusion. Not ionized drug molecules dissolved in the aqueous phase pass through the semi-permeable lipid membrane to the aqueous phase on the other side of the membrane. Rate of this process depends on inter alia the solubility of the drug in lipids, as indicated by lipophilicity. ${ }^{12}$

Lipinski's rule of five which describes molecular properties important for drug pharmacokinetics in the human body says that an orally drug is active with $\log \mathrm{P} \leq 5 .^{13}$

Lipophilicity can be determined experimentally by classical extraction method in the system octanol-water. However, this method has been practically superseded by 
chromatographic techniques, which are simpler and more exact. ${ }^{14}$

In present work we evaluated chromatographic lipophilicity parameters of 27 potentially active thiazolo[3,2-a]pyrimidine derivatives using reversed phase thin layer chromatography (RP-TLC) and reversed phase high performance liquid chromatography (RP-HPLC) methods and compared them with computed $\log \mathrm{P}$ values.

The series of novel 2-halomethyl-2,3dihydrothiazolo[3,2-a]pyrimidine derivatives were synthesized via the reaction of 3-allyl-2-thiouracils with iodine chloride or bromine in anhydrous methanol..$^{15,16} \mathrm{~A}$ bromine and nitro group was introduced by electrophilic substitution at C-6 of the thiazolopyrimidine system. The subsequent hydrogen iodide and bromine elimination provided thiazolo[3,2- $a]$ pyrimidin-5-one derivatives.

\section{Experimental}

Thiazolo[3,2-a]pyrimidin-5-one derivatives 1-27 synthesized according to the literature ${ }^{15,16}$ were initially divided into 3 groups: (2-iodomethyl-2,3-dihydrothiazolo[3,2- $a$ ] pyrimidin-5-one derivatives 1-11, 2-bromomethyl-2,3dihydrothiazolo[3,2-a]pyrimidin-5-one derivatives 12-16 and thiazolo[3,2-a]pyrimidin-5-one derivatives 17-27) basing on their chemical structure (Table 1).

Lipophilicity was determined by chromatographic methods, using RP-TLC and RP-HPLC.

\section{Reversed-phase TLC}

HPTLC Silica gel $60 \mathrm{RP}-18 \mathrm{WF}_{254} \mathrm{~s} 10 \times 10 \mathrm{~cm}$ plates (Merck, Germany) were applied as stationary phase. The solvents: methanol and water for HPLC from POCH (Poland) were used. Compounds were dissolved in methanol $\left(3 \mathrm{mg} \mathrm{mL}^{-1}\right)$, samples $(0.01 \mathrm{~mL})$ of each class was applied on individual plates than dried on air. Methanol concentration expressed as volume fraction $\mathrm{v} / \mathrm{v}$, varied in the range from 0.5 to 0.8 in constant steps of 0.05 . The plates were developed in horizontal DS-chamber (Chromdes, Poland) using saturated conditions (20 min of saturation in ambient temperature). The developing distance was $8 \mathrm{~cm}$. Developed plates were air dried and observed under $254 \mathrm{~nm}$ ultraviolet lamp.

For all the compounds, the relative lipophilicity $R_{M}$ values for seven methanol-water mobile phases were calculated by the use of the formula:

$\mathrm{R}_{\mathrm{M}}=\log \left[\frac{1-\mathrm{R}_{\mathrm{F}}}{\mathrm{R}_{\mathrm{F}}}\right]$
In order to determine the lipophilicity parameters $R_{\mathrm{M} 0}$, linear relationship were calculated between $R_{M}$ values and the methanol's concentration in the mobile phase:

$\mathrm{R}_{\mathrm{M}}=\mathrm{R}_{\mathrm{M} 0}+\mathrm{S} \varphi$

where $R_{M 0}$ is value extrapolated to zero methanol concentration, $\varphi$ is methanol concentration in the mobile phase (in volume fraction v/v), $\mathrm{S}$ is the slope of the regression curve. All experiments were performed in a stable temperature of $22^{\circ} \mathrm{C}$.

\section{Reversed-phase HPLC}

The HPLC experiments were performed on the Shimadzu HPLC system (Japan) equipped with solvent delivery pump LC-20AD, UV-VIS detector model SPD-20A, degasser model DGU-20A5, an column oven model CTO-20A and a column LiChrospher(TM) 100 RP-18 (5 $\mu \mathrm{m})$, Merck (Germany). Mobile phase methanol/ water varied in the various ratios. The solvents: methanol and water for HPLC from POCH (Poland) were used. Methanol concentration expressed as volume fraction $\mathrm{v} / \mathrm{v}$, varied in the range from 0.55 to 0.9 in constant steps of 0.05 . Compounds were dissolved in methanol $\left(1 \mathrm{mg} \mathrm{mL}^{-1}\right)$. Sample injection volume was $0.02 \mathrm{~mL}$. The capacity factor $\mathrm{k}$ was calculated by relationship:

$\mathrm{k}=\frac{\mathrm{t}_{\mathrm{R}}}{\mathrm{t}_{\mathrm{M}}}-1$

where $t_{R}$ is retention time and $t_{M}$ is the time for dead volume (measured by use of uracil).

In order to determine the lipophilicity parameters, linear relationship were calculated between log $\mathrm{k}$ values and the methanol's concentration in the mobile phase:

$\log \mathrm{k}=\log \mathrm{k}_{\mathrm{w}}+\mathrm{S} \varphi$

where $\log \mathrm{k}_{\mathrm{w}}$ is value extrapolated to zero methanol concentration, $\varphi$ is methanol concentration in the mobile phase (in volume fraction $\mathrm{v} / \mathrm{v}$ ), $\mathrm{S}$ is the slope of the regression curve. All experiments were performed in temperature of $22^{\circ} \mathrm{C}$.

Subsequent chromatographic lipophilicity parameter $\varphi_{0}{ }^{14,17}$ was calculated, for RP-TLC method (equation 5) and for RP-HPLC method (equation 6), respectively:

$\varphi_{0}=-\frac{\mathrm{R}_{\mathrm{M} 0}}{\mathrm{~S}}$ 
$\varphi_{0}=-\frac{\log \mathrm{k}_{\mathrm{w}}}{\mathrm{S}}$

\section{Results and Discussion}

$\mathrm{R}_{\mathrm{M} 0}$ and $\log \mathrm{k}_{\mathrm{w}}$ lipophilicity parameters were determined for 27 thiazolo[3,2-a]pyrimidin-5-one derivatives that due to the construction were divided into three groups: 2-iodomethyl-2,3-dihydrothiazolo[3,2-a] pyrimidin-5-one derivatives (1-11), 2-bromomethyl-2,3dihydrothiazolo[3,2-a]pyrimidin-5-one derivatives (12-16) and 2-methylthiazolo[3,2-a]pyrimidin-5-one derivatives (17-27) (Table 1). Methanol was chosen as the most recommended organic modifier of the mobile phases for lipophilicity estimation by RP-TLC and RP-HPLC, since it does not disturb the hydrogen bonding network of water. ${ }^{18,19}$

The linear dependence between $R_{M}$ or $\log k$ values and concentration of organic modifier in the eluent is observed. High values of correlation coefficients $(r=0.92-0.99$ for RP-TLC and $r>0.99$ for RP-HPLC method) were observed for all three groups of compounds in wide range of methanol concentration in mobile phase which permitted determination of lipophilicity parameters: $\mathrm{R}_{\mathrm{M} 0}$ and $\log \mathrm{k}_{\mathrm{w}}$ by extrapolation and $\varphi_{0}$ by interpolation (Table 2 ).

For all the analyzed compounds $\mathrm{R}_{\mathrm{M} 0}$ parameters determined by RP-TLC had lower values than the $\log \mathrm{k}_{\mathrm{w}}$ parameters determined by RP-HPLC (Figure 2).

The corresponding relationship between compound's structure and lipophilicity parameters values were observed (Table 1). The presence of the aliphatic chains or rings in pyrimidine ring induced an increase of $\mathrm{R}_{\mathrm{M} 0}$ and $\log \mathrm{k}_{\mathrm{w}}$ values. The highest value of lipophilicity parameters, both determined by TLC and HPLC, was observed for compounds $\mathbf{1 1}$ and $\mathbf{2 7}$ with cyclohexylmethyl group at C-7. $\log \mathrm{k}_{\mathrm{w}}$ was 4.04 and 3.83, and $\mathrm{R}_{\mathrm{M} 0} 2.94$ and 2.81, respectively for compound $\mathbf{1 1}$ and $\mathbf{2 7}$. The presence of a penta-, hexa- or heptamethylene ring in 2-iodomethyl2,3-dihydrothiazolo[3,2-a]pyrimidin-5-ones (1-3) and thiazolo[3,2-a]pyrimidin-5-ones (17-19) increased the hydrophobicity. For those compounds the experimentally determined lipophilicity parameters were higher in comparison to the derivatives containing substituents on the aliphatic chains and/or electron withdrawing group. The presence of the nitro group at C-6 (compounds 5, 13,

Table 1. Structures of thiazolo[3,2-a]pyrimidin-5-one derivatives

\begin{tabular}{|c|c|c|c|c|c|}
\hline Compound & Core & $\mathrm{R}^{1}$ & $\mathrm{R}^{2}$ & $\mathrm{R}_{\mathrm{M} 0}$ & $\log \mathrm{k}_{\mathrm{w}}$ \\
\hline 1 & & \multicolumn{2}{|c|}{$-\left(\mathrm{CH}_{2}\right)_{3}-$} & 1.67 & 2.07 \\
\hline 2 & & \multicolumn{2}{|c|}{$-\left(\mathrm{CH}_{2}\right)_{4}-$} & 1.65 & 2.51 \\
\hline 3 & & \multicolumn{2}{|c|}{$-\left(\mathrm{CH}_{2}\right)_{5}-$} & 2.32 & 2.95 \\
\hline 4 & & $\mathrm{H}$ & $\mathrm{CH}_{3}$ & 1.43 & 1.57 \\
\hline 5 & & $\mathrm{NO}_{2}$ & $\mathrm{CH}_{3}$ & 1.21 & 1.95 \\
\hline 6 & & $\mathrm{H}$ & $\mathrm{H}$ & 1.04 & 1.30 \\
\hline 7 & & $\mathrm{CH}_{3}$ & $\mathrm{CH}_{3}$ & 1.54 & 1.99 \\
\hline 8 & & $\mathrm{CH}_{3}$ & $\mathrm{H}$ & 1.22 & 1.71 \\
\hline 9 & & $\mathrm{Br}$ & $\mathrm{CH}_{3}$ & 1.52 & 2.11 \\
\hline 10 & & $\mathrm{H}$ & $\mathrm{C}_{2} \mathrm{H}_{5}$ & 1.49 & 2.00 \\
\hline 11 & & $\mathrm{H}$ & $\mathrm{CH}_{2} \mathrm{C}_{6} \mathrm{H}_{11 \mathrm{cykl}}$ & 2.94 & 4.04 \\
\hline 12 & & $\mathrm{H}$ & $\mathrm{CH}_{3}$ & 1.06 & 1.35 \\
\hline 13 & & $\mathrm{NO}_{2}$ & $\mathrm{CH}_{3}$ & 1.32 & 1.94 \\
\hline 14 & & $\mathrm{CH}_{3}$ & $\mathrm{CH}_{3}$ & 1.38 & 1.76 \\
\hline 15 & & $\mathrm{CH}_{3}$ & $\mathrm{H}$ & 1.01 & 1.76 \\
\hline 16 & & $\mathrm{Br}$ & $\mathrm{CH}_{3}$ & 1.56 & 2.08 \\
\hline 17 & & \multicolumn{2}{|c|}{$-\left(\mathrm{CH}_{2}\right)_{3}-$} & 1.48 & 1.80 \\
\hline 18 & & \multicolumn{2}{|c|}{$-\left(\mathrm{CH}_{2}\right)_{4}-$} & 2.01 & 2.30 \\
\hline 19 & & \multicolumn{2}{|c|}{$-\left(\mathrm{CH}_{2}\right)_{5}-$} & 2.17 & 2.67 \\
\hline 20 & & $\mathrm{H}$ & $\mathrm{CH}_{3}$ & 1.06 & 1.26 \\
\hline 21 & & $\mathrm{NO}_{2}$ & $\mathrm{CH}_{3}$ & 1.47 & 1.88 \\
\hline 22 & & $\mathrm{H}$ & $\mathrm{H}$ & 0.77 & 0.91 \\
\hline 23 & & $\mathrm{CH}_{3}$ & $\mathrm{CH}_{3}$ & 1.36 & 1.72 \\
\hline 24 & & $\mathrm{CH}_{3}$ & $\mathrm{H}$ & 1.03 & 1.40 \\
\hline 25 & & $\mathrm{Br}$ & $\mathrm{CH}_{3}$ & 1.46 & 2.01 \\
\hline 26 & & $\mathrm{H}$ & $\mathrm{C}_{2} \mathrm{H}_{5}$ & 1.17 & 1.75 \\
\hline 27 & & $\mathrm{H}$ & $\mathrm{CH}_{2} \mathrm{C}_{6} \mathrm{H}_{11 \mathrm{cyk} \mid}$ & 2.81 & 3.83 \\
\hline
\end{tabular}

$\mathrm{R}_{\mathrm{M} 0}$ : value extrapolated to zero methanol concentration; $\log \mathrm{k}_{\mathrm{w}}$ : decimal $\log$ arithm $(\log \mathrm{P})$ of partition coefficient $\mathrm{P}$. 
Table 2. The lipophilicity parameters calculated from RP-TLC and RP-HPLC experimental values

\begin{tabular}{|c|c|c|c|c|c|c|c|c|}
\hline \multirow[t]{2}{*}{ Compound } & \multicolumn{4}{|c|}{ RP-TLC ${ }^{a}$ method } & \multicolumn{4}{|c|}{ RP-HPLC ${ }^{\text {b }}$ method } \\
\hline & $\mathrm{R}_{\mathrm{M} 0}^{\mathrm{c}}$ & $\mathrm{S}^{\mathrm{d}}$ & $\varphi_{0}{ }^{\mathrm{e}}$ & $\mathbf{R}^{\mathrm{f}}$ & $\log \mathrm{k}_{\mathrm{w}}{ }^{\mathrm{g}}$ & $\mathrm{S}^{\mathrm{d}}$ & $\varphi_{0}{ }^{\mathrm{e}}$ & $R^{f}$ \\
\hline 1 & 1.67 & 2.417 & 0.692 & 0.9805 & 2.07 & 2.969 & 0.697 & 0.9968 \\
\hline 2 & 1.65 & 2.327 & 0.707 & 0.9565 & 2.51 & 3.315 & 0.758 & 0.9973 \\
\hline 3 & 2.32 & 3.221 & 0.720 & 0.9910 & 2.95 & 3.729 & 0.791 & 0.9979 \\
\hline 4 & 1.43 & 2.355 & 0.607 & 0.9447 & 1.57 & 2.590 & 0.604 & 0.9970 \\
\hline 5 & 1.21 & 2.206 & 0.547 & 0.9707 & 1.95 & 3.320 & 0.587 & 0.9967 \\
\hline 6 & 1.04 & 1.907 & 0.544 & 0.9634 & 1.30 & 2.404 & 0.539 & 0.9972 \\
\hline 7 & 1.54 & 2.396 & 0.644 & 0.9761 & 1.99 & 2.919 & 0.683 & 0.9978 \\
\hline 8 & 1.22 & 1.997 & 0.609 & 0.9180 & 1.71 & 2.725 & 0.629 & 0.9977 \\
\hline 9 & 1.52 & 2.357 & 0.643 & 0.9762 & 2.11 & 3.031 & 0.683 & 0.9988 \\
\hline 10 & 1.49 & 2.341 & 0.638 & 0.9727 & 2.00 & 2.956 & 0.698 & 0.9981 \\
\hline 11 & 2.94 & 3.744 & 0.786 & 0.9774 & 4.04 & 4.727 & 0.677 & 0.9986 \\
\hline 12 & 1.06 & 1.874 & 0.567 & 0.9621 & 1.35 & 2.421 & 0.854 & 0.9976 \\
\hline 13 & 1.32 & 2.215 & 0.597 & 0.9716 & 1.94 & 3.141 & 0.556 & 0.9986 \\
\hline 14 & 1.38 & 2.180 & 0.633 & 0.9468 & 1.76 & 2.716 & 0.618 & 0.9972 \\
\hline 15 & 1.01 & 1.704 & 0.595 & 0.9964 & 1.76 & 2.721 & 0.647 & 0.9980 \\
\hline 16 & 1.56 & 2.347 & 0.665 & 0.9250 & 2.08 & 2.985 & 0.647 & 0.9989 \\
\hline 17 & 1.48 & 2.141 & 0.690 & 0.9266 & 1.80 & 2.392 & 0.698 & 0.9943 \\
\hline 18 & 2.01 & 2.728 & 0.735 & 0.9799 & 2.30 & 2.788 & 0.753 & 0.9957 \\
\hline 19 & 2.17 & 2.933 & 0.741 & 0.9837 & 2.67 & 3.169 & 0.824 & 0.9971 \\
\hline 20 & 1.06 & 1.765 & 0.603 & 0.9789 & 1.26 & 1.984 & 0.843 & 0.9920 \\
\hline 21 & 1.47 & 2.147 & 0.684 & 0.9710 & 1.88 & 2.499 & 0.636 & 0.9973 \\
\hline 22 & 0.77 & 1.470 & 0.522 & 0.9618 & 0.91 & 1.704 & 0.752 & 0.9913 \\
\hline 23 & 1.36 & 2.003 & 0.681 & 0.9600 & 1.72 & 2.330 & 0.532 & 0.9952 \\
\hline 24 & 1.03 & 1.651 & 0.623 & 0.9478 & 1.40 & 2.095 & 0.737 & 0.9944 \\
\hline 25 & 1.46 & 2.019 & 0.722 & 0.9604 & 2.01 & 2.577 & 0.669 & 0.9977 \\
\hline 26 & 1.17 & 1.736 & 0.676 & 0.9524 & 1.75 & 2.428 & 0.779 & 0.9963 \\
\hline 27 & 2.81 & 3.300 & 0.850 & 0.9795 & 3.83 & 4.264 & 0.719 & 0.9980 \\
\hline
\end{tabular}

${ }^{a}$ RP-TLC: reversed phase thin layer chromatography; ${ }^{b} \mathrm{RP}-\mathrm{HPLC}$ : reversed phase high performance liquid chromatography; ${ }^{\mathrm{c}} \mathrm{R}_{\mathrm{M} 0}$ is value extrapolated to zero methanol concentration; ${ }^{\mathrm{d} S}$ : slope of the regression curve; ${ }^{\mathrm{e}} \varphi_{0}$ : chromatographic lipophilicity parameter; ${ }^{\mathrm{f}} \mathrm{R}$ : correlation coefficient; ${ }^{\mathrm{g}} \log \mathrm{k}_{\mathrm{w}}$ : decimal $\log$ arithm $(\log \mathrm{P})$ of partition coefficient $\mathrm{P}$.

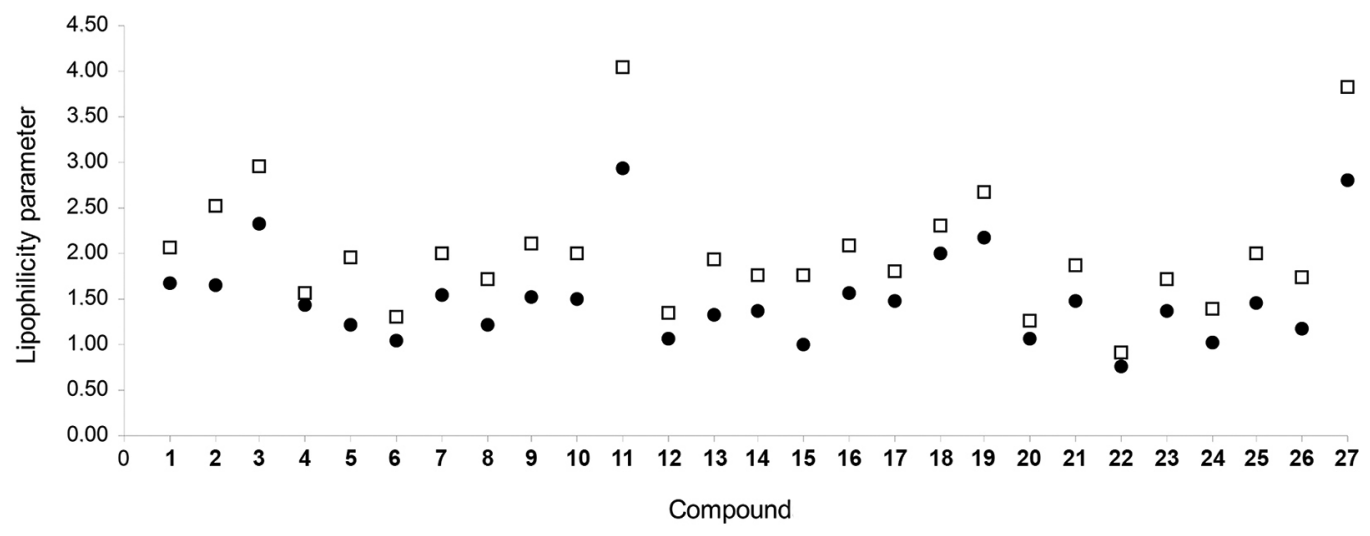

Figure 2. The relationship between $\mathrm{R}_{\mathrm{M} 0}(\bullet)$ and $\log \mathrm{k}_{\mathrm{w}}(\square)$ values of compounds 1-27.

21) increases the $\log \mathrm{k}_{\mathrm{w}}$ value compared to the hydrogen atom (compounds $4, \mathbf{1 2}, \mathbf{2 0}$ ). A similar relationship appears on the parameter $\mathrm{R}_{\mathrm{M} 0}$ with the exception of 2-iodomethyl derivatives $\mathbf{4}$ and $\mathbf{5}$. Simultaneously reduce the values of the lipophilicity parameters compared to $\mathrm{CH}_{3}$ group in the case of 2,3-dihydrothiazolopyrimidin-5-ones $\mathbf{7}$ and $\mathbf{1 4}$ with the exception of $\log \mathrm{k}_{\mathrm{w}}$ parameter value for 13 and 14. In the case of 2-methylthiazolo[3,2-a]pyrimidin-5-ones, the $\mathrm{R}_{\mathrm{M} 0}$ and $\log \mathrm{k}_{\mathrm{w}}$ values are slightly higher for derivative $\mathbf{2 1}$ containing $\mathrm{NO}_{2}$ group as compared with a derivative $\mathbf{2 3}$ 
containing $\mathrm{CH}_{3}$ at $\mathrm{C}-6$. The presence of the bromine atom at $\mathrm{C}-6$ affects the growth lipophilicity parameters compared to the compounds containing $\mathrm{H}$ and $\mathrm{CH}_{3}$ in the case of 2-bromomethyl-2,3-dihydrotiazolo[3,2-a]pyrimidin-5-ones (compounds 12, 14, 16) and thiazolo[3,2-a]pyrimidin5-ones (compounds 20, 23, 25). For 2-iodomethyl-2,3dihydrotiazolo $[3,2-a]$ pyrimidin-5-ones a slight decrease in the values $\mathrm{R}_{\mathrm{M} 0}$ and the $\log \mathrm{k}_{\mathrm{w}}$ was observed in the case of the bromine atom presence at C-6 compared to hydrogen atom (compounds $\mathbf{4 , 9}$ ).

Analysis of $\log \mathrm{k}_{\mathrm{w}}$ values showed a characteristic dependence of this parameter on the substituents present in the 2-position of the thiazolopyrimidine system (Figure 3).

The derivatives containing the same substituents on the pyrimidine ring and the different substituents at $\mathrm{C}-2$ of the thiazole ring were examined. For all studied groups of compounds (except for group 4) higher values of $\log \mathrm{k}_{\mathrm{w}}$ for derivatives containing an iodomethyl group at $\mathrm{C}-2$ was observed (Figure 3a). The presence of bromomethyl group causes a slight decrease in the value of this parameter (Figure $3 b$ ). The lowest values of $\log \mathrm{k}_{\mathrm{w}}$ are characteristic for derivatives containing a methyl group at the $\mathrm{C}-2$ and the double bond between $\mathrm{C}-2$ and $\mathrm{C}-3$ in a thiazolopyrimidine system (Figure 3c). In the case the lipophilicity parameters were calculated by computational methods an identical relationship were observed (Table 3). Compounds having a methyl group at C-6 and hydrogen at C-7 (Figure 3, group 4), have a slightly higher values of $\log \mathrm{k}_{\mathrm{w}}$ for 2-bromomethyl derivative $\mathbf{1 5}$ in comparison with 2-iodomethyl derivative 8. For $\mathrm{R}_{\mathrm{M} 0}$ values from the above-described relationship, only in the case of compounds containing a methyl group at C-7 and hydrogen at C-6 or a methyl group at C-6 and C-7 was observed (Figure 4, groups 1 and 3). Minor deviations from the above described relationships in the case of groups 4 and 5 may be observed due to the innacurate reading of the $R_{\mathrm{f}}$ value.

Relative lipophilicity $\mathrm{R}_{\mathrm{M} 0}$ and $\log \mathrm{k}_{\mathrm{w}}$ values were compared with $\log \mathrm{P}$ values calculated by computational methods (Table 3). ${ }^{20}$

The multivariate comparison of the experimentally obtained values and the coefficients calculated by the computational methods was made by principal component analysis (PCA).

The experimental data $\left(\log \mathrm{k}_{\mathrm{w}}, \mathrm{R}_{\mathrm{M} 0}\right)$ from Table 2 and the calculated $\log \mathrm{P}$ parameters (from Table 3 ) were grouped as data matrix and were analyzed using PCA, based on the covariance matrix (unscaled PCA) using Statistica 12 and the results are presented in Figure 5.

PCA resulted in two principal components that account for the majority of the data variability, i.e., 91.51 and 4.27 for PC1 and PC2, respectively, giving $95.78 \%$ in total.

The best correlations between the experimental (or extrapolated) partition coefficients and miLOGP parameters were obtained. Generally, higher values of the partition coefficient for these relationships were obtained for RP TLC method.

The best correlations between partition coefficients $\mathrm{R}_{\mathrm{M} 0}-\log \mathrm{k}_{\mathrm{w}}$, ALOGPS-XLOGP2, MLOGP-ALOGP were obtained.

It can be seen that experimentally determined chromatographic indices are less correlated with computational ones, which is an additional argument about the sense of this study.

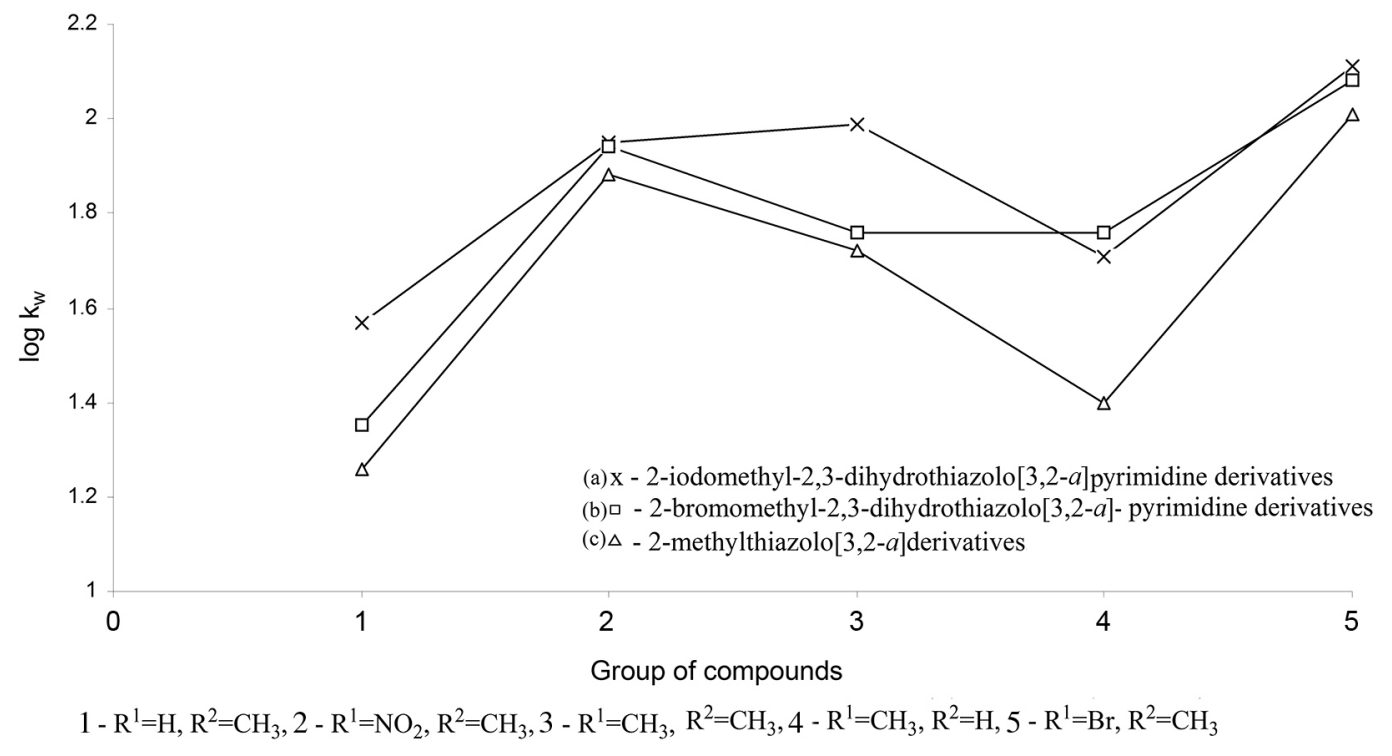

Figure 3. The relationship between $\log \mathrm{k}_{\mathrm{w}}$ values according to core and the substituents. 


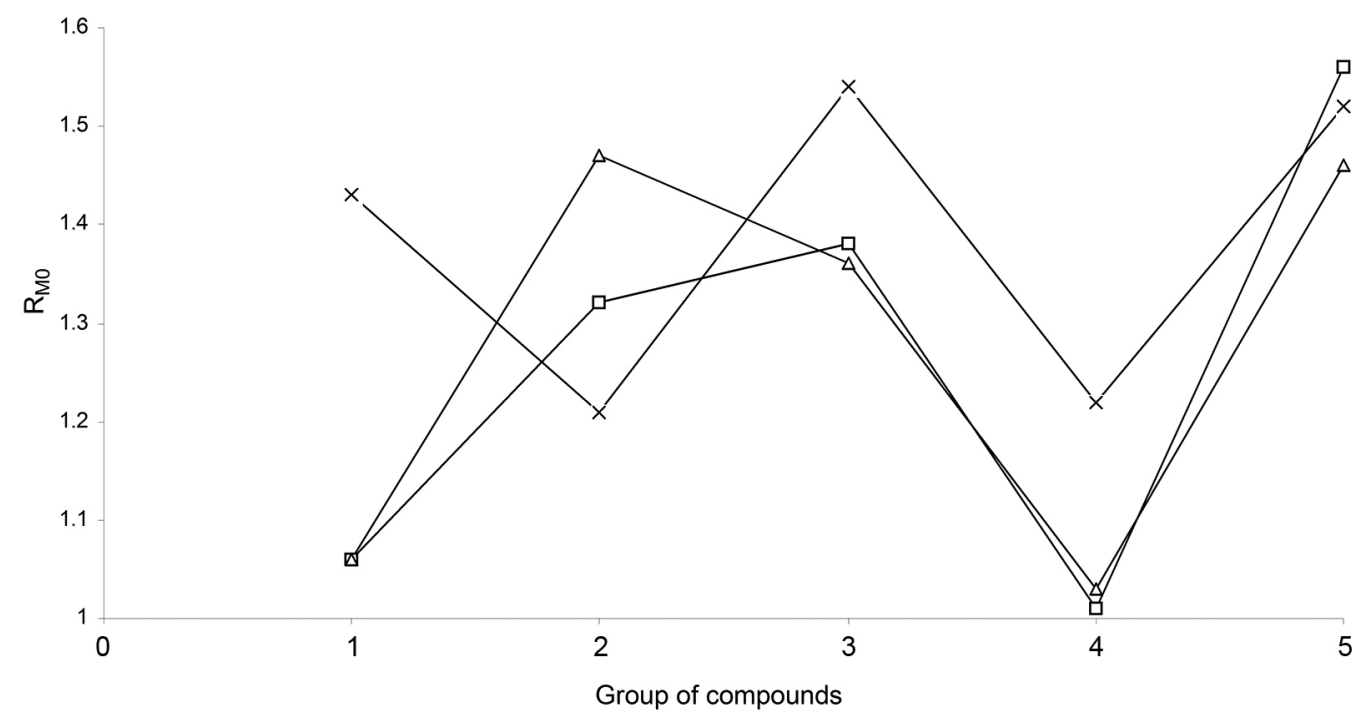

$1-\mathrm{R}^{1}=\mathrm{H}, \mathrm{R}^{2}=\mathrm{CH}_{3}, 2-\mathrm{R}^{1}=\mathrm{NO}_{2}, \mathrm{R}^{2}=\mathrm{CH}_{3}, 3-\mathrm{R}^{1}=\mathrm{CH}_{3}, \mathrm{R}^{2}=\mathrm{CH}_{3}, 4-\mathrm{R}^{1}=\mathrm{CH}_{3}, \mathrm{R}^{2}=\mathrm{H}, 5-\mathrm{R}^{1}=\mathrm{Br}, \mathrm{R}^{2}=\mathrm{CH}_{3}$

(a) $\mathrm{X}$ - 2-iodomethyl-2,3-dihydrothiazolo[3,2- $a]$ pyrimidine derivatives (b) $\mathrm{-}$ - 2-bromomethyl-2,3-dihydrothiazolo[3,2-a]- pyrimidine derivatives (c) $\Delta$ - 2-methylthiazolo[3,2-a]derivatives

Figure 4. The relationship between $\mathrm{R}_{\mathrm{M} 0}$ values according to core and the substituents.

Table 3. The comparison $\mathrm{R}_{\mathrm{M} 0}$ and $\log \mathrm{k}_{\mathrm{w}}$ values of compounds 1-27 with $\log \mathrm{P}$ values calculated by computing programs

\begin{tabular}{|c|c|c|c|c|c|c|c|c|c|}
\hline Compound & $\mathrm{R}_{\mathrm{M} 0}$ & $\log k_{w}$ & $\operatorname{miLog} \mathrm{P}$ & XLOGP2 & XLOGP3 & ALOGPS & MLOGP & ALOGP & $\mathrm{AC} \log \mathrm{P}$ \\
\hline 1 & 1.67 & 2.07 & 2.18 & 1.33 & 2.02 & 2.20 & 2.76 & 2.96 & 2.18 \\
\hline 2 & 1.65 & 2.51 & 2.70 & 1.90 & 2.56 & 2.49 & 3.04 & 3.42 & 2.50 \\
\hline 3 & 2.32 & 2.95 & 3.20 & 2.47 & 3.10 & 2.88 & 3.30 & 3.87 & 2.82 \\
\hline 4 & 1.43 & 1.57 & 1.74 & 1.38 & 1.72 & 2.24 & 2.19 & 2.36 & 1.72 \\
\hline 5 & 1.21 & 1.95 & 1.63 & 1.59 & 1.76 & 1.83 & 2.19 & 2.11 & 1.09 \\
\hline 6 & 1.04 & 1.30 & 1.30 & 0.83 & 1.35 & 2.06 & 1.89 & 1.85 & 0.94 \\
\hline 7 & 1.54 & 1.99 & 2.12 & 1.52 & 2.09 & 2.27 & 2.48 & 2.81 & 2.11 \\
\hline 8 & 1.22 & 1.71 & 1.73 & 0.97 & 1.72 & 2.18 & 2.19 & 2.30 & 1.33 \\
\hline 9 & 1.52 & 2.11 & 2.48 & 2.09 & 2.62 & 2.73 & 2.89 & 2.82 & 2.17 \\
\hline 10 & 1.49 & 2.00 & 2.32 & 1.63 & 2.15 & 2.82 & 2.48 & 2.89 & 2.18 \\
\hline 11 & 2.94 & 4.04 & 4.23 & 4.07 & 4.35 & 3.99 & 3.80 & 4.59 & 3.40 \\
\hline 12 & 1.06 & 1.35 & 1.47 & 1.18 & 1.38 & 1.34 & 2.04 & 1.83 & 1.38 \\
\hline 13 & 1.32 & 1.94 & 1.36 & 1.39 & 1.41 & 1.41 & 2.04 & 1.57 & 0.75 \\
\hline 14 & 1.38 & 1.76 & 1.85 & 1.32 & 1.75 & 1.65 & 2.34 & 2.28 & 1.77 \\
\hline 15 & 1.01 & 1.76 & 1.46 & 0.77 & 1.38 & 1.37 & 2.04 & 1.76 & 0.99 \\
\hline 16 & 1.56 & 2.08 & 2.21 & 1.89 & 2.28 & 2.21 & 2.75 & 2.28 & 1.83 \\
\hline 17 & 1.48 & 1.80 & 1.67 & 0.25 & 1.22 & 1.65 & 1.83 & 1.51 & 1.41 \\
\hline 18 & 2.01 & 2.30 & 2.18 & 0.82 & 1.76 & 2.05 & 2.12 & 1.96 & 1.73 \\
\hline 19 & 2.17 & 2.67 & 2.69 & 1.39 & 2.30 & 2.46 & 2.40 & 2.42 & 2.05 \\
\hline 20 & 1.06 & 1.26 & 1.23 & 0.30 & 0.92 & 1.10 & 1.21 & 0.91 & 0.95 \\
\hline 21 & 1.47 & 1.88 & 1.12 & 0.51 & 0.96 & 0.96 & 1.21 & 0.65 & 0.33 \\
\hline 22 & 0.77 & 0.91 & 0.79 & -0.25 & 0.55 & 0.68 & 0.88 & 0.40 & 0.17 \\
\hline 23 & 1.36 & 1.72 & 1.61 & 0.44 & 1.30 & 1.42 & 1.53 & 1.36 & 1.34 \\
\hline 24 & 1.03 & 1.40 & 1.22 & -0.11 & 0.92 & 1.05 & 1.21 & 0.84 & 0.56 \\
\hline 25 & 1.46 & 2.01 & 1.97 & 1.01 & 1.83 & 1.77 & 1.95 & 1.36 & 1.40 \\
\hline 26 & 1.17 & 1.75 & 1.80 & 0.55 & 1.36 & 1.43 & 1.53 & 1.43 & 1.41 \\
\hline 27 & 2.81 & 3.83 & 3.71 & 2.99 & 3.56 & 3.63 & 2.94 & 3.14 & 2.63 \\
\hline
\end{tabular}

$\mathrm{R}_{\mathrm{M} 0}$ : value extrapolated to zero methanol concentration; $\log \mathrm{k}_{\mathrm{w}}$ : decimal $\log$ arithm $(\log \mathrm{P})$ of partition coefficient $\mathrm{P}$. 


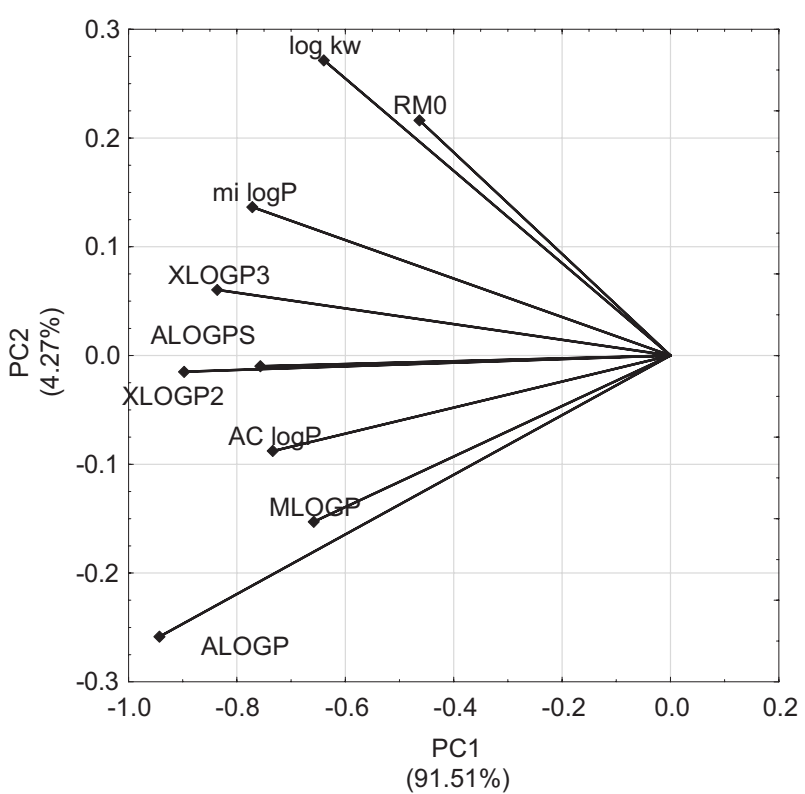

Figure 5. Experimental and calculated data projection on the plane determined by two first principal components.

\section{Conclusions}

The lipophilicity of 27 potentially active thiazolo[3,2-a $]$ pyrimidine derivatives were evaluated by using reversedphase thin-layer chromatography and reversed-phase high performance liquid chromatography techniques. The linear correlation between $\mathrm{R}_{\mathrm{M}}$ and $\log \mathrm{k}$ values and the concentration of methanol in the mobile phase for all compounds were obtained.

For $\log \mathrm{k}_{\mathrm{w}}$ the higher correlation coefficients were observed in comparison to $\mathrm{R}_{\mathrm{M} 0}$, which indicates that for the tested group of compounds, RP-HPLC method is more exact.

For all of analyzed compounds, determined lipophilicity's parameters values are $>0$, which means that there are hydrophobic substances, soluble in the lipid phase. Simultaneously these values are $<5$, i.e., are in accordance with Lipinski's rule in the range of lipophilicity. In case of being used as drugs, they will be active after oral application.

\section{Acknowledgments}

This work has been supported by Nicolaus Copernicus University, Collegium Medicum as part of statutory research project in 2015 year, No. 473.

\section{References}

1. Kennis, L. E. J.; Vandenberk, J.; Mertens, J. C.; EP Patent 110,435 1984.
2. den Boer, J. A.; Vahlne, J. O.; Post, P.; Heck, A. H.; Daubenton, F.; Olbrich, R.; Hum. Psychopharm. Clin. 2000, 15, 179.

3. Back, T.; Prado, R.; Zhao, W. Z.; Watson, B. D.; Ginsberg, M. D.; Neurol. Res. 1998, 20, 643.

4. Cornish, J. W.; Maany, I.; Fudala, P. J.; Ehrman, R. N.; Robbins, S. J.; O’Brien, C. P.; Drug Alcohol Depend. 2001, 61, 183.

5. Strome, E. M.; Clark, C. M.; Zis, A. P.; Doudet, D. J.; Biol. Psychiatry 2005, 57, 1004.

6. Russo, F.; Guccione, S.; Romeo, G.; Barretta, G. U.; Pucci, S.; Caruso, A.; Amico-Roxas, M.; Cutuli, V.; Eur. J. Med. Chem. 1993, 28, 363.

7. Beversdorf, D. Q.; Nordgren, R. E.; Bonab, A. A.; Fischman, A. J.; Weise, S. B.; Dougherty, D. D.; Felopulos, G. J.; Zhou, F. C.; Bauman, M. L.; J. Neuropsychiatry Clin. Neurosci. 2012, 24, 191.

8. Danel, K.; Pedersen, E. B.; Nielsen, C.; J. Med. Chem. 1998, 41, 191.

9. Pecorari, P.; Rinaldi, M.; Costantino, L.; Provvisionato, A.; Cermelli, C.; Portolani, M.; Farmaco 1991, 46, 899.

10. Ram, V. J.; Vanden Berghe, D. A.; Vlietinck, A. J.; Ann. Chem. 1987, 797.

11. Seperic, M.; DE. Patent 21,40,601 1972.

12. Zejc, A.; Gorczyca, M.; Drugs Chemistry; Wydawnictwo Lekarskie PZWL: Warszawa, 2002.

13. Lipinski, C. A.; Lombardo, F.; Dominy, B. W.; Feeney, P. J.; Adv. Drug Delivery Rev. 2012, 64, 4.

14. Jóźwiak, K.; Szumiło, H.; Soczewiński, E.; Wiadomości Chemiczne 2001, 55, 1047.

15. Studzińska, R.; Wróblewski, M.; Dramiński, M.; Heterocycles 2008, 75, 1953.

16. Studzińska, R.; Wróblewski, M.; Karczmarska-Wódzka, A.; Kołodziejska, R.; Tetrahedron Lett. 2014, 55, 1384.

17. Valko, K.; Slegel, P. J.; J. Chromatogr. 1993, 631, 49.

18. Komsta, Ł.; Skibiński, R.; Berecka, A.; Gumieniczek, A.; Radkiewicz, B.; Radoń, M.; J. Pharm. Biomed. Anal. 2010, 53, 911 .

19. Giaginis, C.; Tsantili-Kakoulidou, A.; J. Liq. Chromatogr. Relat. Technol. 2008, 31, 79.

20. Tetko, I. V.; Gasteiger, J.; Todeschini, R.; Mauri, A.; Livingstone, D.; Ertl, P.; Palyulin, V. A.; Radchenko, E. V.; Zefirov, N. S.; Makarenko, A. S.; Tanchuk, V. Y.; Prokopenko, V. V.; J. Comput.-Aided Mol. Des. 2005, 19, 453; VCCLAB, Virtual Computational Chemistry Laboratory, http://www. vcclab.org accessed in January 2016.

Submitted: October 19, 2015 Published online: February 2, 2016 